\title{
社会的比較に基づく洞察の促進・抑制
}

\author{
有賀 敦紀 ${ }^{1}$ 立正大学
}

\section{Facilitation and inhibition of insightful problem solving based on social comparison}

\author{
Atsunori Ariga (Rissho University)
}

\begin{abstract}
Intuitively, insight emerges unexpectedly. However, some previous views proposed that insight emerges with a high probability after people recognize their failure in solving a problem. In order to empirically investigate this failure-insight relationship, this study manipulated when participants recognized failure by using social comparison. It presumed that participants who had not yet solved the problem but knew others had already solved it would recognize that their currently adopted strategy was a failure; the timing of this was manipulated in the experiment. As expected, participants who were given a cover story regarding others' fast performance for the T-puzzle completed the same puzzle more successfully, as compared to those who were given a story of others' slow performance. The results suggest that the occurrence of insight was influenced by when participants recognized their failure. Providing social reality information (i.e., others' good/poor performance) might be a method to facilitate or inhibit insightful problem solving.
\end{abstract}

Key words: problem solving, insight, social comparison, T-puzzle.

The Japanese Journal of Psychology

2013, Vol. 83, No. 6, pp. 576-581

人間の認知活動は創造的である。例えば “いつも利 用する通学路が工事中で利用できない場合，別のどの 経路を利用すべきか”, “自販機の下に落ちたコインを 手持ちの道具を使って拾うにはどうすべきか”、“読み 手にわかりやすい文章を書くには，どのように段落を 構成すべきか”など，人間は日常生活において様々な 問題に直面するが，それらを適切に解決することがで きる。このような日常における問題の中には，過去に 経験した解法に基づいて解を導き出せるものもあれ ば，まったく新しい解を創造する必要のある問題も数 多く存在する。特に, 後者の問題を解決するための認 知活動は洞察と呼ばれる (Mayer, 1992)。そして, 洞 察が生じると，あたかも突然解が “ひらめいた”よう に飛躍的に問題が解決される（Davidson，1995; Metcalfe \& Wiebe, 1987; Wallas, 1926)。本研究の目的 は，問題解決において突発的に生じる印象のある “ひ らめき”が，外的に操作され得るのかを調べることで ある。

これまで洞察の生起に関して, 失敗の重要性が指摘

Correspondence concerning this article should be sent to: Atsunori Ariga, Department of Psychology, Rissho University, Osaki, Shinagawa-ku, Tokyo 141-8602, Japan (e-mail: ariga@ris.ac.jp)

1 本研究は立正大学心理学部の坂本真裕子さん (平成 23 年 度卒業生）の協力のもとに行われた。ここに謝意を表する。
されてきた(鈴木・開, 2003)。例えば, 問題空間アプ ローチ (Kaplan \& Simon, 1990; MacGregor, Ormerod, \& Chronicle, 2001）によれば, 問題解決が始まると, 解決者はある特定の問題空間内を探索する。しかし, 洞察を必要とする問題解決においては, 初期に探索す る問題空間の中に解は存在しない可能性が高い（イン パス＝行き詰まり）。そこで, 解決者は初期の誤った 問題空間内の探索を打ち切り, 別の（適切な）問題空 間を探索して解を発見しなければならない。つまり， 解決者が洞察に至るためには, 問題空間の移行が必要 となる。このとき, 初期の問題空間の探索結果が不調 に終わること, すなわち失敗が, 解決者に問題空間の 移行を促すと考えられている (MacGregor et al., 2001)。

また，制約の動的緩和理論（開・鈴木，1998）に代 表される制約論的アプローチ（阿部・中川，2006; 地 村・松岡・駒崎・中川・楠見, 1999; Knoblich, Ohlsson, Haider, \& Rhenius, 1999; Knoblich, Ohlsson, \& Raney, 2001; Ohlsson, 1992; 鈴木・宮崎・開，2003） は, “制約の緩和”を洞察が生起するための重要なプ ロセスとしている。一般に問題解決における解決者 は, 問題空間を隈なく探索するわけではなく, 適切な 制約を設定して効率的に解を得ようとする（ヒューリ スティクス)。具体的には, これまでの経験や問題の 
性質から, 解決者は問題解決において不必要とされる 思考を避ける。つまり，制約とは，問題における情報 量を絞り込むための解決者の内的傾向性を指し, この 制約に基づいて問題空間は構成される。制約は，過去 の経験に基づいて解が得られるようなタイプの問題に おいては, 効率的な解決をもたらす。しかし, 洞察を 必要とする問題解決では, しばしばこの制約が解決を 妨害する。なぜなら，解決者は制約に固執すること で, 解の無い問題空間を探索し続けるというインパス に陥る可能性が高いからである。インパスに陷ると， 解決者は（不適切な）制約内で様々な方略を試行錯誤 するため, 必然的に失敗を重ねることになる。しか し, 失敗の蓄積によって制約は徐々に緩和され，ある 時点で確率的にひらめきが生じ, 解決者は洞察に至 る。

上述した二つのアプローチは, 問題空間を所与のも のとして捉えるか (問題空間アプローチ), 問題空間 を制約に基づいて構成されたものとして捉えるか（制 約論的アプローチ）という違いはある。しかし，いず れのアプローチも, 失敗を洞察が生起するための重要 なプロセスとして捉えている点で共通している。問題 空間アプローチでは, 失敗が解決者に別の問題空間へ の移行を促すと考えるのに対して（Kaplan \& Simon, 1990; MacGregor et al., 2001), 制約論的アプローチで は, 失敗が解決者に制約の緩和を生じさせ, 新たな情 報の問題空間への取り込みを促すと考える（Seifert, Meyer, Davidson, Patalano, \& Yaniv, 1995)。本研究の 目的は，二つのアプローチの違いを検証することでは なく, 二つのアプローチが共に注目している, 洞察に おける失敗の重要性を検証することである。これま で, 失敗の認識を独立変数として実験的に操作して, 洞察の生起を従属変数として調べた研究はない。そこ で本研究では, 社会心理学において提唱されている社 会的比較理論（Festinger, 1954）に基づき, 実験参加 者が問題解決中に方略の失敗を認識するタイミングを 実験的に操作して, 洞察が促進・抑制されるのかを調 べた。なお, 本研究に打ける “方略” とは, 問題解決 において解を発見するための解決者の方針を指す。ま た, “失敗の認識”とは, 現在採用している方略を維 持しても解決しないことを, 解決者が顕在的あるいは 潜在的に認識することを指す。

社会的比較理論では, 人間は他者との比較を通じ て, 自己の様々な側面を正確に評価しょうとする欲求 を持つとされている。つまり，人間は他者の意見や行 動といった社会的実在性を参照することで，自己の意 見や行動の妥当性を確認する。本研究では, 他者があ る問題を解決するまでに要した時間（解決時間）を社 会的実在性として実験参加者に与えた。具体的には, 実験参加者が問題解決に取り組む前に, カバーストー リーとして他者の良い成績（短い解決時間）あるいは
他者の悪い成績（長い解決時間）が呈示された。この とき, 他者の良い成績が呈示された実験参加者は, 社 会的比較を通じて早い段階（呈示された解決時間が経 過した時点）で自分が現在行っている方略が失敗であ ると認識する可能性が高い。一方, 他者の悪い成績が 呈示された実験参加者は, 比較的長い間（呈示された 解決時間が経過するまで), 自分が現在行っている方 略を維持して, 初期の問題空間の中に解を求め続ける 可能性が高い。結果として, 前者では洞察の生起が促 進され, 後者では洞察の生起が抑制されることが予測 される。

\section{方 法}

実験参加者 男子大学生 38 名, 女子大学生 72 名の 計 110 名（平均年齢 20.1 歳）を実験参加者とした。

課題 実験参加者の課題は, 四つの木製のピース (The T・扔もちゃ箱イカロス社) を組み合わせて T 字型を作るというパズル（Tパズル）を完成させるこ とであった（Figure 1)。このパズルでは，“Tは縦棒 と横棒から成っている”という信念から，ほとんどの 解決者は縦棒と横棒を個別に作成しょうとし, 五角形 (Figure 1 内 $\alpha$ のピース) の凹部分を埋めることに大 半の時間を費やすことがわかっている。このことか ら, Tパズルは洞察を必要とする問題として適切であ るとされている（開・鈴木，1998）。

手続き 実験は個室で 1 人ずつ実施された。最初に 実験参加者は, 時計や携带電話など実験参加者が時間 を確認することができるものは，すべてカバンの中に 入れるよう指示された。実験参加者の課題は, $\mathrm{T}$ 字の 台紙（A4 用紙に T パズルの完成形の外枠を印刷した もの）の上にできるだけ速く Tパズルを完成させる ことであった。このとき, 制限時間は 30 分であるこ とが伝えられた。実験中, 実験者は後らを向いていた ため, 実験参加者はパズルが完成したらすぐに実験者 に合図するよう教示された。実験参加者が $\mathrm{T}$ 字を完 成させるまでの時間（完成時間）がストップウォッチ で計測された。実験終了後（実験参加者がパズルを完 成させた後あるいは 30 分の制限時間が経過した後), 実験者は実験参加者にディブリーフィングを行い, $\mathrm{T}$
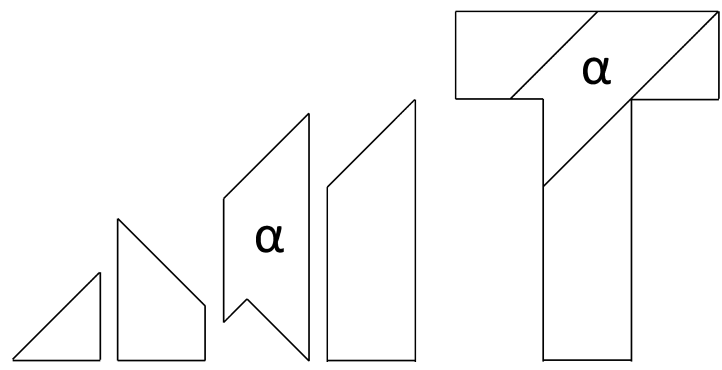

Figure 1. T パズルの初期状態（左）および完成状態（右） 
パズルの経験の有無と, 最後まで課題に集中していた のかについて回答を求めた。

条件 実験参加者は以下の三つの条件に無作為に割 り当てられた。(a)統制条件の実験参加者（34 名）は

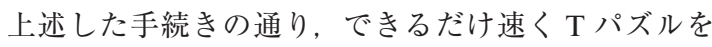
完成させた。その結果, 実験参加者の平均完成時間は 10 分 12 秒であった。(b) 5 分条件の実験参加者 (38 名）は上述した手続きに加え, “他の人は 5 分で解い ているパズルです”と実験前に教示された。つまり， 5 分条件の実験参加者には, 統制条件の成績よりも良 い他者の成績（偽りの情報）が事前に知らされた。(c) 20 分条件の実験参加者（38 名）は上述した手続きに 加え, “他の人は 20 分で解いているパズルです”と実 験前に教示された。つまり，20 分条件の実験参加者 には, 統制条件の成績よりも悪い他者の成績（偽りの 情報）が事前に知らされた。

仮説 制限時間内（30 分以内）に $\mathrm{T}$ パズルを完成

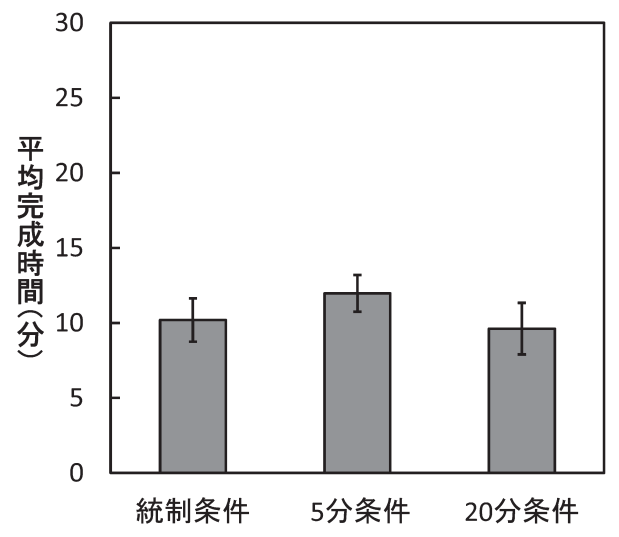

Figure 2. 各条件における完成者の平均完成 時間（バーは標準誤差を表す）

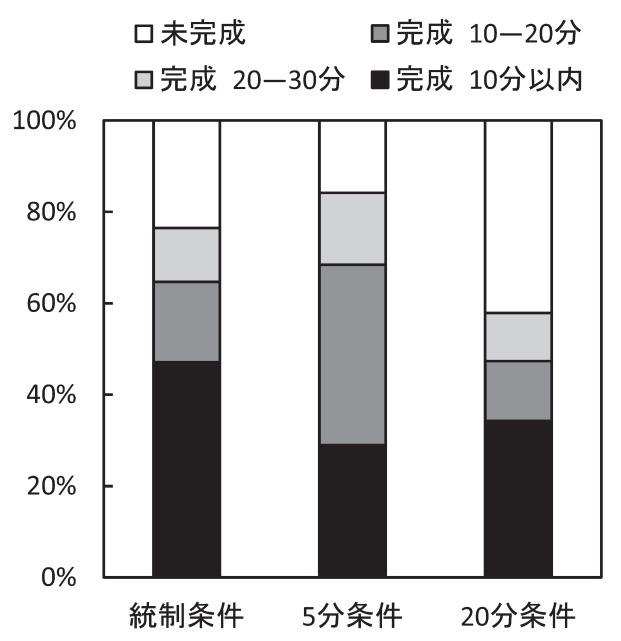

Figure 3. 各条件における 10 分ごとの完成者 の比率
させた実験参加者（完成者）の平均完成時間と完成者 の比率を実験参加者の成績とした。5 分条件の実験参 加者の成績が統制条件の実験参加者の成績よりも良 く,さらに 20 分条件の実験参加者の成績が統制条件 の実験参加者の成績よりも悪かったのであれば，実験 参加者が問題解決において方略の失敗を認識する夕イ ミングによって, 洞察の生起が促進・抑制されたと結 論できる。

\section{結果}

内省報告の結果から，これまでに $\mathrm{T}$ パズルを経験 した実験参加者はいなかった。また，すべての実験参 加者は最後まで課題に集中していたと回答した。

まず，制限時間内にパズルを完成させた実験参加者 (完成者: 統制条件 26 名, 5 分条件 32 名, 20 分条件 22 名）の平均完成時間を条件ごとに算出して,

Figure 2 に表した。1 要因 3 水準 (条件: 統制条件, 5 分条件, 20 分条件) の分散分析を行ったところ, 条 件の主効果は有意でなかった $(F(2,77)=0.95, n s)$ 。

次に，課題時間を 10 分ごとに区分し，各時間区分 の完成者数および未完成者数を条件別に分類して，そ の比率を Figure 3 に表した。 $\chi^{2}$ 検定を行った結果, 各時間区分における完成者の比率と条件の間に有意な 効果が得られた $\left(\chi^{2}(6)=13.53, p<.05\right)$ 。残差分析の 結果, 10 分経過してから 20 分経過するまでの完成者 の比率は, 5 分条件において期待値よりも有意に高く $(z=2.84, p<.005), 20$ 分条件において期待值よりも 有意に低い傾向があることが見出された $(z=-1.88$, $p=.06)$ 。一方, 制限時間内にパズルを完成させるこ とができなかった未完成者の比率は，5分条件におい て期待值よりも有意に低く $(z=-1.97, p<.05), 20$ 分条件において期待值よりも有意に高いことが見出さ れた $(z=2.54, p<.05)$ 。

\section{考察}

本研究の目的は, 問題解決において突発的に生じる 印象のあるひらめきが, 外的に操作され得るのかを調 べることであった。そのために, 社会的比較理論に基 づき, 実験参加者が問題解決中に方略の失敗を認識す るタイミングを実験的に操作して, 洞察の生起が促 進・抑制されるのかを調べた。実験参加者が T パズ ルを開始する前に, 実験参加者に他者の完成時間を呈 示したところ (5 分条件 vs. 20 分条件), 洞察の生起 に関して有意な効果が認められた。さらに, 課題開始 後 10 分経過してから 20 分経過するまでの間の完成者 の比率は, 5 分条件において期待值よりも有意に高 く, 20 分条件において期待值よりも有意に低い傾向 があった。また，最終的な未完成者の比率は，5分条 件において期待值よりも有意に低く, 20 分条件にお いて期待值よりも有意に高いことがわかった。したが 
って，本研究の結果は仮説を支持するものであった。 予測通り，5 分条件の実験参加者は，社会的比較を通 じて早い段階（5 分程度が経過した時点）で自分が現 在行っている方略が失敗であると認識したと考えられ る。一方, 20 分条件の実験参加者は, 比較的長い間 (20 分程度が経過するまで), 自分が現在行っている 方略を維持して, 初期の問題空間の中に解を求め続け たと考えられる。結果として, 前者では課題開始後 10 分経過してから 20 分経過するまでの間に洞察の生 起が促進され，後者では 20 分経過するまでの間に洞 察の生起が抑制される傾向があった（結果的に多くの 実験参加者が制限時間内に洞察に至ることはなかっ た)。この結果は, 洞察に扔ける失敗の重要性を主張 するこれまでの理論（問題空間アプローチや制約論的 アプローチ）との整合性が高い。本研究の実験参加者 は, 他者の完成時間に依存して異なるタイミングで失 敗を認識し, そのタイミングに応じて問題空間の移行 (Kaplan \& Simon, 1990) や制約の緩和（また，その 結果として制約からの逸脱; 開・鈴木, 1998）が生じ ていたと解釈できる。このプロセスは顕在的あるいは 潜在的に進行し, 本研究で観察された洞察の促進・抑 制現象を生み出していたと考えられる。さらに, 完成 者の平均完成時間に注目すると, 本研究では条件の有 意な効果は見られなかった。このことは，5分条件 (あるいは 20 分条件) において実験参加者の洞察の生 起が総じて速く（あるいは遅く）なったのではないこ とを示唆している。完成者の比率の結果と併せて考え ると，他者の成績が洞察に与える影響は，本来比較的 早い段階（課題開始から 10 分以内）で解決できる実 験参加者においてはそれほど生じず，それ以外の比較 的遅い段階で解決に至る実験参加者および解決に至ら ない実験参加者において生じ得ると考えられる。

ただし，本研究の実験参加者は課題開始前に与えら れた他者の成績に基づいて, これから行う課題の困難 度を予測していた可能性がある。そして，予測された 困難度が, 実験参加者の課題に対するモチベーション に影響を与えたかもしれない。例えば，20 分条件の 実験参加者は課題が難しいと予測した結果, モチべー ションを低下させた状態で課題に臨んだ可能性が考え られる。この可能性を検証するために, 本研究では追 加調査 $(N=34$, 平均年齢 20.8 歳, 男性 10 名) を行 った。追加調査では実験と同様の刺激を用いて, 調査 参加者を統制条件 (10 名)，5 分条件 (12 名)，20 分 条件（12 名）に無作為に割り当てて, 個別に課題の 困難度を予測させた（5 件法：1=非常に易しい，5= 非常に難しい)。調查参加者には以下の教示を行った。 “ここにある四つのピースを使って T 字型を作るとい うパズルがあります。あなたはこれから自分でこのパ ズルを完成させるとして，どの程度易しいあるいは難 しいと予測しますか。５分条件と 20 分条件では以上
の教示に加えて, 実験と同様に他者の完成時間が伝え られた。統制条件では他者の完成時間は伝えられなか つた。調査の結果, 統制条件の調査参加者が予測した 平均困難度は $3.90(S D=1.30), 5$ 分条件の調查参加 者が予測した平均困難度は $3.00(S D=1.23), 20$ 分条 件の調查参加者が予測した平均困難度は 3.08（ $S D=$ 0.95) であった。1 要因 3 水準の分散分析を行ったと ころ, 条件の主効果は有意でなかった $(F(2,31)=$ $1.77, n s)$ 。なお， T パズルを経験したことのある調査 参加者はいなかった。追加調査の結果から, 実験の参 加者が課題前に予測した困難度も, 条件間で同程度で あった（むしろ統制条件で高かったかもしれない）と 推測できる。したがって, 少なくとも課題を開始した 時点では, 実験参加者のモチベーションが条件間で異 なっていたとは考えにくい。実際，実験において，課 題開始後 10 分間は完成者の比率に条件の有意な効果 は認められなかった。加えて, 実験参加者の意識的な 報告（内省報告）の範囲内では，すべての条件におい て制限時間が経過するまで手を止めて課題をあきらめ た実験参加者はいなかった。したがって, 本研究の結 果が, 各条件における実験参加者のモチベーションの 違いから生まれた可能性は低いと考えられる。

洞察による問題解決を検討した先行研究を概観する と, 解に関わる重要なヒントが解決者に与えられたと きに，洞察は促進され得ることがわかる。例えば，放 射線問題（Duncker, 1945）では，同型の問題を実験 参加者にヒントとして呈示することで, 実験参加者の 正答率は上昇した（Gick \& Holyoak, 1980)。チェッカ ーボード問題 (Wickelgren, 1974) では, 升目にヒント となる文字を書くことで実験参加者の問題解決は促進 された（Kaplan \& Simon, 1990)。また, 放射線問題 や 2 本のひも問題 (Maier, 1931) に掞いて, 解と一 致する眼球運動や身体運動を実験参加者に行わせてヒ ントを無意識的に与えても, 実験参加者の洞察の生起 は促進されることが報告されている（Thomas \& Lleras, 2007, 2009)。しかし, ヒントが洞察の生起を 促進しないという報告もある。例えば, 9 点問題 (Wickelgren, 1974）では, “枠の外にはみ出す”とい う重要なヒントを実験参加者に与えても, 問題解決の 成績は改善されなかった（Weisberg \& Alba, 1981）。 また， 2 本のひも問題では，実験者がひもにぶつかる ことで実験参加者にヒントを呈示しても, 実験参加者 の解決が促進されることはなかった（Landrum, 1990)。このように, 当該問題に固有のヒントを実験 者が解決者に与えることは, 必ずしも問題解決におい て洞察を促進するわけではない。本研究では実験者が 実験参加者に他者の成績を呈示するだけで, 洞察の生 起は促進されることがわかった。この社会的比較理論 に基づく実験操作は, 解決者に問題に固有のヒントを 与えるという操作よりも汎用可能性が高く, Tパズル 
以外の問題解決においても安定した促進効果が得られ ると推察される。

例えば, 洞察を必要とする問題解決における社会的 影響を調べた研究として, 清河・伊澤・植田（2007） の研究がある。実験参加者の課題は, 本研究と同様に Tパズルを完成させることであった。(a)統制条件の実 験参加者は 1 人でパズルに取り組んだ。(b)自己観察条 件の実験参加者はパズルに取り組んでいる最中, 20 秒㧍きに自身の直前の取り組みをディスプレイで観察 した。(c)他者観察条件の実験参加者は 2 人ペアにな り, 一方がパズルに取り組んでいる最中，他方は相手 の取り組みをディスプレイで観察した。ただし，20 秒㧍きにこの役割を交替した。その結果，他者観察条 件でのみ問題解決が促進された。この促進効果は, 実 験参加者が自身の取り組みとは異なるパターンの他者 の取り組みを観察することで, 制約から冕脱したパ夕 ーンを遂行しやすくなった結果であると解釈された。 つまり, 解決者に問題に固有のヒントが与えられなく ても, 解決者が他者の取り組みを観察するだけで, 洞 察の生起は促進されることが報告されている。本研究 の結果と併せて考えると, 解決者に呈示する他者の成 績を社会的実在性として操作したり, 解決者に他者の 行為を観察させたりといった社会的要因を操作するこ とは, 問題解決において洞察を促進させるための有効 な普遍的手法の開発につながると考えられる。

本研究の結果に基づいて, 今後の検討課題が何点か 挙げられる。第一に, 解決者に他者の成績を呈示する という実験操作が，Tパズル以外の問題においても洞 察を促進させ得るのかを確かめる必要がある。第二 に, 課題中の解決者のピースの置き方を厳密に分析す ることで, 解決者の失敗の認識と方略の変化との関係 をより詳細に考察できるようになると考えられる。第 三に, 解決者の社会的比較の対象となる集団の質や量 を検討することで, 洞察を必要とする問題解決におけ る社会的実在性の効果を, より強固に主張できるよう になると考えられる。

本研究では, 問題解決に扔いて突発的に生じる印象 のあるひらめきが, 他者の成績に関する解決者の事前 知識によって, 促進・抑制されることを明らかにし た。この結果は, 洞察の生起に関するこれまでの説明 理論から予測される結果と一致する。解決者は社会的 比較を通じて失敗の認識を行い, そのタイミングに応 じて洞察に至ったと考えられる。つまり, 洞察は外的 に操作可能な現象であり, 解決者に他者の成績を伝え て方略の失敗を認識させることが, 洞察を促進させる ための有効な手法であると言える。本研究で得られた 知見は, 個人の認知機能を訓練する様々な場面（教育 現場など）での応用につながると考えられる。

\section{引用文献}

阿部 慶賀 · 中川 正宣 (2006). 洞察的問題解決過程 における過去試行からの回避傾向が解決過程に及 ぼす影響 認知科学, 13, 187-204.

(Abe, K., \& Nakagawa, M. (2006). Effects of avoidance from past failure on the process of insight problem solving. Cognitive Studies, 13, 187204.)

Davidson, J. E. (1995). The suddenness of insight. In R. J. Sternberg \& J. E. Davidson (Eds.), The nature of insight. Cambridge, MA: MIT Press. pp. 125155.

Duncker, K. (1945). On problem-solving. Psychological Monographs, 58, 1-113.

Festinger, L. (1954). A theory of social comparison processes. Human Relations, 7, 117-140.

Gick, M. L., \& Holyoak, K. J. (1980). Analogical problem solving. Cognitive Psychology, 12, 306355.

開一夫・鈴木 宏昭 (1998). 表象変化の動的緩和理 論——洞察メカニズムの解明に向けて——認知 科学, 5, 69-79.

(Hiraki, K., \& Suzuki, H. (1998). Dynamic constraints relaxation as a theory of insight. Cognitive Studies, 5, 69-79.)

地村 弘二・松岡 隆史 - 駒崎 久明 - 中川 正宣 - 楠見 孝（1999）。 カオスニューラルネットワークによ る漢字記憶探索プロセスのダイナミカルなモデル 化 認知科学, 6, 44-54.

(Jimura, K., Matsuoka, T., Komazaki, H., Nakagawa, M., \& Kusumi, T. (1999). Dynamical model of searching memory for Chinese characters using chaotic neural network. Cognitive Studies, 6 , 44-54.)

Kaplan, C. A., \& Simon, H. A. (1990). In search for insight. Cognitive Psychology, 22, 374-419.

清河 幸子・伊澤 太郎・植田 一博 (2007)。洞察問題 解決に試行と他者観察の交替が及ぼす影響の検討 教育心理学研究, 55, 255-265.

(Kiyokawa, S., Izawa, T., \& Ueda, K. (2007). Role exchange between task-doing and observing others as a means of facilitating insight problem-solving. Japanese Journal of Educational Psychology, 55, 255-265.)

Knoblich, G., Ohlsson, S., Haider, H., \& Rhenius, D. (1999). Constraint relaxation and chunk decomposition in insight problem-solving. Journal of Experimental Psychology: Learning, Memory, and Cognition, 25, 1534-1555.

Knoblich, G., Ohlsson, S., \& Raney, G. E. (2001). An eye movement study of insight problem solving. Memory \& Cognition, 29, 1000-1009.

Landrum, R. E. (1990). Maier's (1931) two-string problem revisited: Evidence for spontaneous transfer. Psychological Reports, 67, 1079-1088.

MacGregor, J. N., Ormerod, T. C., \& Chronicle, E. P. 
(2001). Information processing and insight: A process model of performance on the nine-dot and related problems. Journal of Experimental Psychology: Learning, Memory, and Cognition, 27, 176-201.

Maier, N. R. F. (1931). Reasoning in humans: 2. The solution of a problem and its appearance in consciousness. Journal of Comparative \& Physiological Psychology, 12, 181-194.

Mayer, R. E. (1992). Thinking, problem solving, cognition. New York: W. H. Freeman and Company.

Metcalfe, J., \& Wiebe, D. (1987). Intuition in insight and noninsight problem solving. Memory \& Cognition, 15, 238-246.

Ohlsson, S. (1992). Information processing explanations of insight and related phenomena. In M. T. Keane \& K. J. Gilhooly (Eds.), Advances in the psychology of thinking. Vol. 1. Hertfordshire, UK: Harvester. pp. 1-44.

Seifert, C. M., Meyer, D. E., Davidson, N., Patalano, A. L., \& Yaniv, I. (1995). Demystification of cognitive insight: Opportunistic assimilation and the prepared-mind perspective. In R. J. Sternberg \& J. E. Davidson (Eds.), The nature of insight. Cambridge, MA: MIT Press. pp. 65-124.

鈴木 宏昭・開一夫 (2003). 洞察問題解決への制約 論的アプローチ 心理学評論, 46, 211-232.

(Suzuki, H., \& Hiraki, K. (2003). Constraint approach to insight problem-solving. Japanese Psychological Review, 46, 211-232.)

鈴木 宏昭・宮崎 美智子・開一夫（2003）。制約論か ら見た洞察問題解決における個人差 心理学研 究, 74, 336-345.

(Suzuki, H., Miyazaki, M., \& Hiraki, K. (2003). Constraint-based approach to individual differences in insight problem-solving. Japanese Journal of Psychology, 74, 336-345.)

Thomas, L. E., \& Lleras, A. (2007). Moving eyes and moving thought: On the spatial compatibility between eye movements and cognition. Psychonomic Bulletin \& Review, 14, 663-668.

Thomas, L. E., \& Lleras, A. (2009). Swinging into thought: Directed movement guides insight in problem solving. Psychonomic Bulletin \& Review, 16, 719-723.

Wallas, G. (1926). The art of thought. New York: Harcourt Brace Jovanovich.

Weisberg, R. W., \& Alba, J. W. (1981). An examination of the alleged role of "fixation" in the solution of several "insight" problems. Journal of Experimental Psychology: General, 110, 169-192.

Wickelgren, W. A. (1974). How to solve problems. San Francisco: Freeman.

- 2012.3. 7 受稿, 2012. 7.7 受理—— 